\title{
Delegation, Committees, AND Managers
}

\author{
BIRGER WERNERFELT \\ MIT Sloan School of Management \\ 38 Memorial Drive \\ Cambridge, MA 02142 \\ bwerner@mit.edu
}

\begin{abstract}
Attempts to economize on decision-making time imply that groups of peers may delegate authority to a small committee of managers even though this means that the information and preferences of the uninvolved players are neglected. Decisions are more likely to be delegated to players with better information and more representative preferences. The possibility of ex post protests may force managers to take the preferences of others into account but may also give them incentives to ignore their private information. The argument may explain employees' willingness to let bosses decide, and thus throw some light on the theory of the firm.
\end{abstract}

\section{INTRODUCTION}

The President of the United States makes lots of decisions on behalf of the electorate. Because most voters disagree with some of these decisions, one could ask why we do not submit them to votes or some other mechanism allowing broader influence. More participation would allow decisions to be made in light of more information and a wider set of preferences. We propose to explain this by arguing that it would be prohibitively expensive and time-consuming for each member of the electorate to participate in the decisions currently made by the chief executive. It is simply more efficient to delegate decisions, even at the cost of giving up influence. To mitigate the obvious dangers of ceding decision rights, the President is selected based on forecasts about the decisions he will make, and his decision-making rights are subject to ex post controls such as congressional reversal or reelection/ impeachment. The threat of ex post intervention is, however, designed to be less acute than would be possible.

\footnotetext{
I am grateful for comments from a coeditor, two anonymous referees, Bob Gibbons, Jon Levin, and Eric Van den Steen as well as participants in seminars at MIT, the Organizational Economics Conference at the University of Toronto, and the 2005 meetings of the American Economic Association. Any errors and omissions are, of course, the responsibility of the author.
}

(C) 2007, The Author(s)

Journal Compilation (C) 2007 Blackwell Publishing

Journal of Economics E Management Strategy, Volume 16, Number 1, Spring 2007, 35-51 
The fundamental premise of the paper, in the words of Barnard (1968), is that "The making of decisions, as everyone knows from personal experience, is a burdensome task." Several studies have documented the importance of decision-making costs in individual level decisions, including investment and saving (Madrian and Shea, 2001; Choi et al., 2006), brand choice (Hauser and Wernerfelt, 1990), and price setting (Zbaracki et al., 2004). We will here be concerned with group level decisions, primarily concerning production. Some of these decisions may appear minor, but we will argue that most productive activities require a very, very large number of decisions to be made and that it takes a noninfinitesimal amount of time to be involved in each of them. Let us look at a description of managerial decision-making from the literature.

Mintzberg (1973) followed five CEOs for one week each and even though they supposedly deal with "big" questions, he reports that half of the activities they engaged in lasted less than nine minutes (p. 242). It is instructive to reproduce some examples of decisions made by the CEO's in the book.

- Is it worth spending resources looking into new equipment? (p. 233)

- Do we allow a specific exception from an operating procedure? (p. 246)

- What is our position on a fee for rework done by a supplier? (p. 23435)

- How do we react to a solicitation from our trade association? (p. 246)

- Should we adopt a new operating procedure? (p. 246)

- Should we use money to celebrate the firm's tenth birthday? (pp. 23334)

- Will we grant a client's wish for a change in work being done? (p. 248)

- Should we contribute to a charitable organization? (p. 248).

Individually, each of these decisions took very little time, but there were a lot of them and they all had to be made.

The in- and outgoing mail provides another angle on the constant demands for managerial attention: On the average, the men were asked to process 36 pieces of mail per day (p. 242), but they themselves initiated only one piece per day (p. 248). The bulk of managerial decision-making consists in reacting to external events, rather than planning grand strategies. Consistent with this, most of the decisions listed above were initiated by others and they often arrived at unpredictable times. ${ }^{1}$ One of the jobs of the CEO is simply to be around such that the organization can react to unanticipated developments as they take place.

1. Apart from making decisions, a large part of the managers' time went with information gathering activities, presumably because this enabled them to make better decisions. In contrast to the decision-making activities, information gathering tends to be more predictably scheduled-in the form of regular reports or meetings. 
In companies above a minimum size, the CEO doesn't even make all the decisions. Many decision-rights are delegated to lower level employees, and the CEO does not participate at all-presumably because it is too costly to involve him. As one would expect, many of these are "smaller" decisions, and the pace is even higher. In a study of 56 foremen Guest (1956) finds that they average 583 activities per 8 hour shift (one every 48 seconds)!

\subsection{PLAN OF THE PAPER}

As noted above, we will argue that decision-making costs can explain delegation to committees/managers and the design of the control systems under which they work. We briefly review the literature in Section 2, and in Section 3 present a model of peer-group decisionmaking in which we can evaluate the efficiency of delegating decisionmaking rights to a small committee. We find that the optimal number of managers is lower when if it takes more time to make the decision, if biases are smaller and less important, if there are fewer players, and if public information is better. We also find that players make better managers if their information is better and if their preferences are closer to the group average. In Section 4, we proceed to evaluate the effect of a control system under which nonmanagers can protest. We consider two cases, one in which decisions can be changed, and one in which the manager is subject to contractual or otherwise credible discipline. In both cases we find that a desire to avoid protests may restrain the selfishness of committee members and thus allow committees to be smaller. This does not depend on protests having direct costs for management; the effect is driven by a desire to "get away with" a bit of selfishness, rather than none. However, if a protest exposes management to direct costs, we show that the threat of it may cause managers to ignore their private information. So in the design of control systems, it is not necessarily good to make protests very easy.

The model has outcomes that look like employment relationships as limiting cases. In these cases a group appoints a single manager, and we found that this is more likely to happen in the presence of repeated play. In the concluding Section 5 we therefore discuss the extent to which the model and the concept of decision-making costs throw light on the theory of the firm. We also note that very similar results can be developed if the argument instead is based on negotiation costs.

\section{Literature}

Leaders and managers are used in a wide variety of settings and we believe that the arguments made and forces identified apply to 
organizations in general, not just to firms. Consider that Homans (1950), in commenting on Whyte's (1943) famous study of the Norton street gang, said that leadership evolved spontaneously and that "the organization of large formal enterprises ... is a rationalization of tendencies that exist in all human groups" (pp. 186-7). Consistent with this, the literature contains many reports on abdication of decision-rights in organizations other than firms. In particular, many groups of equals select managers or representatives and give them decision-rights. (a) In the age of the Vikings, small Nordic villages had a meeting place where the inhabitants met periodically to decide on matters of joint interest, such as what was going to be harvested when. In several places, one can still see a circle of about ten stones used for seating, and we believe that each free household was represented. In contrast, representatives from each village decided matters of regional or national importance. The representative system economized on travel-costs and kept the decisionmaking body smaller and presumably more expedient (Anderson, 1958). (b) Charitable organizations generally start out as very small groups of people making decisions on the basis of consensus. However, as they get bigger, more and more decisions have to be made and they invariably appoint a manager to make the bulk of them. Major issues may be resolved by a board of several members or by vote, but once the organization has grown above a very small size, individual members do not participate in all the decisions (Perkins and Poole, 1996). (c) Cooperatives, in which a number of producers jointly own an entity, such as a dairy, follow a similar pattern. The dairy will have a manager responsible for daily operations, and the owners will vote on larger matters, sometimes with weighted votes (Albaek and Schultz, 1997).

Several angles on the function of management are offered by those concerned with understanding the vertical division of labor within organizations. Different branches of this literature portray the primary function of organizational structures as information processing (Radner, 1993; Meagher, Orbay, and Van Zandt, 2004), resource allocation (Cremer, 1980; Geanakoplos and Milgrom, 1991), monitoring (Calvo and Wellisz, 1978), or task assignment (Garicano, 2000). These models explain why top-management performs different productive tasks than lower-management or workers, but do not directly explain why decision-making rights are ceded to top-management. In principle, organizations could combine democratic decision-making with the optimal vertical division of productive effort.

The literature on decision-rights is much smaller, but still offers several explanations for the commonly observed tendency of groups to ignore the information and opinion of many of their members, instead delegating decision-making to a single one of them. One branch of the 
literature looks at the content of decisions and argues that agents without dictatorial powers may engage in strategically distorted communication (Dessein, 2002; Gilligan and Krehbiel, 1987; Stein, 2002) or may underinvest in information (Aghion and Tirole, 1997). This paper is part of another branch that explains dictatorship by various direct costs of participatory decision-making. Within this branch, Segal (2006) has focused on communication costs, whereas Bajari and Tadelis (2001), Bolton and Rajan (2001), Tadelis (2002), and Wernerfelt (1997) have looked at direct and indirect bargaining costs. We here contribute a third factor by arguing that mere participation requires an agent to spend a noninfinitesimal amount of time in order to understand the decision at hand. $^{2}$

The economic literature explicitly concerned with committee design is very small. The two most closely related papers, Sah and Stiglitz (1988) and Dessein (2003), both associate larger committees with better, but also more costly, decisions. Beyond this, however, their arguments differ from that made here in several ways. Because Sah and Stiglitz do not consider heterogeneous preferences, and Dessein's players participate in decisions whether or not they have any formal decision rights, the identities of committee members are largely irrelevant in their contexts, and neither paper worries about them. Two less closely related papers are by Persico (2004), who looks at the effect of voting rules on committee members' incentives to invest in information, and Harris and Raviv (2007), who look at the optimal committee composition when members with better information also are more biased. ${ }^{3}$

Our argument is consistent with much of the managerial literature on the functions and nature of managers. In particular, this literature often gives as a rationale for leadership the need to make faster decisionsthe unstated implication being that decision-making without leadership will take too much time. Simon (1960) treats "decision making as synonymous with managing." (p. 1) and describes how the different components of decision-making fill up the manager's time-budget. Barnard (1968) writes on the origin of organization that "if all talk at once there is confusion; and there is indecision particularly as to timing of actions. This creates the necessity for a leader."(p. 107). Writing on the nature of managers, Homans (1950, p. 188) argues that the leader is (a)

2. We will ultimately claim that these costs could be large enough to encourage agents to give up influence. This echoes Downs (1957) who, in the context of a modern democracy, claims that individuals face costs of voting that are very large relative their expected benefits.

3. The informational advantage of larger committees is highlighted by the literature on the Condorcet Jury Theorem (Black, 1958). This literature starts with the assumption that each juror will select the better of two alternatives with probability above one half. It then follows that a committee majority is more likely to be right than an individual. 
better informed than other members and (b) "the man that comes closest to realizing the norms the group values highest." Similarly, Simon (1976, p. 135) argues that one function of authority is that decisions are made with the use of expertise. Both of these traits are consistent with the model presented here.

\section{MODEL}

Although we have in mind a situation in which a very large number of decisions have to be made in a short amount of time, we will focus the model on a group of $M$ peers having to solve a single decision-making problem. The problem solving process consists in pooling of information and choice, and we ask how many players should participate in it. It is tempting to involve more players because they contribute different information and represent different preferences; but this temptation is counter-balanced by the time-costs of participation. To keep things simple, we rule out structures in which contribution of information and participation in choice can be separated. That is, an individual player may either participate in the entire problem solving process or delegate decision-making rights to the players that do. We will use the terms "committee members" or "managers" for the latter group of $m \leq M$ decision-makers.

We assume that the group faces a problem characterized by a random variable $x \in X$, where $X$ is a subset of $\mathbf{R}$. To fix ideas, we can think of $x$ as a description of the decision that maximizes the ex ante expected payoffs to the group as a whole. All players share the same zero-mean prior distribution $F$ over $x$, and we denote the variance of $F$ by $\sigma_{x}^{2}$. Each manager $i$ gets an iid personal signal of $x$, denoted by $y_{i}$ and drawn from a distribution with mean $x$ and variance $\sigma_{y}^{2}$. A vector of such signals known by $m$ managers, $\left(y_{1}, y_{2}, \ldots, y_{m}\right)$, induces a posterior distribution of $x$. The mean of this distribution is $\mu\left(y_{1}, y_{2}, \ldots, y_{m}\right)$ and its variance is $\sigma^{2}\left(y_{1}, y_{2}, \ldots, y_{m}\right)$. With some abuse of notation, we will denote the preposterior (ex ante expected) variance by $\sigma^{2}(m)$. More precise posteriors, which ceteris paribus can be achieved by having a larger committee, will be desirable because they allow better decision-making. We model this by using a quadratic cost function such that players prefer to hit a target as closely as possible. Specifically, we assume that player $i$ evaluates a decision $a \in X$ according to the quadratic loss function $\beta(a-$ $\left.x-\theta_{i}\right)^{2}$, where $\theta_{i}$ is a personal bias and $\beta>0$. Still interpreting $x$ as a description of the decision which maximizes the ex ante expected payoffs to the group as a whole, we can think of the $\theta_{i}{ }^{\prime}$ s as individual preferences for suboptimal decisions. The biases are independently drawn from a distribution $G$ with mean zero and variance $\sigma_{\theta}^{2}$. So we can 
think of the biases as deviations from the group average preferences or as preferences for ex ante inefficient outcomes. The $\beta$ s scale the strength of preference relative to the cost of time. Given this loss function, $i^{\prime}$ s preferred decision would be $a_{i}^{*}=\mu+\theta_{i}$, implying an expected loss of $\sigma^{2}\left(y_{1}, y_{2}, \ldots, y_{m}\right)$. The cost of having more committee members is that each of them has to spend a certain amount of time on the decision, such that the total time cost is $m w$, where $w$ is the opportunity cost of the time needed to participate in the decision.

The sequence of events is as follows: (I) The variable describing the ex ante optimal decision $(x)$ is drawn together with the vector of biases $\left(\theta_{1}, \theta_{2}, \ldots, \theta_{M}\right)$, (II) the committee is selected, (III) the managers' private signals $\left(y_{1}, y_{2}, \ldots, y_{m}\right)$ are drawn, (IV) the committee makes its decision, and $(\mathrm{V})$ payoffs are distributed. We will use the term "ex ante" to refer to the point in time before (I).

Because our focus is on the tension between committee members and nonmembers, we do not want to worry about distortions from intermember bargaining. We therefore assume that the managers all share the information $\left(y_{1}, y_{2}, \ldots, y_{m}\right)$ and end up with the same posterior beliefs. This requires that all managers choose to share their private information and do so honestly. Although these are unusual assumptions, they could be justified by a persuasion technology under which any claim made has to be accompanied by so much detail that managers are able to judge its veracity. We further depart from much of the literature (Dessein, 2002, 2003; Gilligan and Krehbiel, 1987; Stein, 2002), and assume that the preferences, here the $\theta_{i}$ 's, are common knowledge. This assumption could possibly be weakened to allow for some uncertainty around expected biases, but in light of the assumed truth-telling among managers, it is not clear that the resulting complications would buy us much. Based on the above set of modeling choices, we assume that the agreed upon (negotiated) decision minimizes the sum of the committee members' losses and thus is

$a_{m}=\arg \min _{a}\left\{a-\left[\mu\left(y_{1}, y_{2}, \ldots, y_{m}\right)+\Sigma_{m} \theta_{j} / m\right]\right\}^{2}$.

To keep the derivations as transparent as possible, we assume for the rest of this section that $X=\mathbf{R}$, such that $a_{m}=\mu\left(y_{1}, y_{2}, \ldots, y_{m}\right)+\Sigma_{m} \theta_{j} / m$. If $i$ is a manager, his expected loss is then simply

$w+\beta \sigma^{2}\left(y_{1}, y_{2}, \ldots, y_{m}\right)+\beta\left[\theta_{i}-\Sigma_{m} \theta_{j} / m\right]^{2}$,

whereas it is $w$ less if he is not a manager. Looking at the problem ex ante, we substitute the preposterior variance $\sigma^{2}(m)$ and find the combined expected loss of all players as

$m w+M \beta \sigma^{2}(m)+\beta \Sigma_{M}\left[\theta_{i}-\Sigma_{m} \theta_{j} / m\right]^{2}$. 
The terms in (3) each shows a different effect of increasing the size of the committee: They capture, in order, the effect of time costs, information, and decision bias. As the number of managers goes up, time costs are increasing and information costs are decreasing, whereas the incremental bias costs depend on the identity $\left(\theta_{j}\right)$ of the managers. Because all arguments will be made in terms of the total costs, we ignore side-payments between the players. We are interested in cases where $M$ is large relative to $m$ and thus assume that the costs of growing $m$ beyond $M / 2$ are larger than the largest possible gains from doing so. Formally, if $s(M / 2)$ is the set of possible committees of size $M / 2$, we assume that $w \geq M \beta \sigma^{2}(M / 2)+\operatorname{Min}_{s(M / 2)}\left\{\beta \Sigma_{M}\left[\theta_{i}-\Sigma_{M / 2} \theta_{j} 2 / M\right]^{2}\right.$. This then guarantees that the optimal $m$ is less than or equal to $M / 2$.

Finding the optimal committee involves solving an NP hard combinatorial optimization problem in which the effect of going from $m$ to $m+1$ managers will depend on the distribution of biases in the group. For example, if $M=4$ and the $\theta^{\prime}$ s are $-1,-1,0$, and 2 , the group will incur smaller bias costs with the best single manager $(1+1+0+4=6)$ than with the best pair of managers $\left(1 / 2^{2}+1 / 2^{2}+\right.$ $1 / 2^{2}+2^{1} / 2^{2}=11^{1} 2^{2}+1{ }^{1} / 2^{2}+{ }^{1} / 2^{2}+11^{1} 2^{2}=7$ ). However, it turns out that the bias costs incurred under the best committee on the average (in $e x$ ante expectation) decreases with $m$, at least as long as $m \leq M / 2$. To see this, observe that the minimal bias costs, $\operatorname{Min}_{s(m)}\left\{\beta \Sigma_{M}\left[\theta_{i}-\right.\right.$ $\left.\left.\Sigma_{m} \theta_{j} / m\right]^{2}\right\}$, are proportional to the variance of the estimated mean from the best among $s(m)$ possible samples of a size $m$. This allows us to make the argument in four simple steps. First, we know from elementary statistics that for a random sample, the expectation of $\beta \Sigma_{M}\left[\theta_{i}-\Sigma_{m} \theta_{j} / m\right]^{2}$ is decreasing in $m$. Second, for a given distribution, we know from extreme value theory that the expected cost of the best among $s$ samples is a decreasing function of $s$. Third, the first two effects reinforce each other because the cost-distribution implied by a smaller sample stochastically dominates that implied by a larger sample. Fourth, $s(m)$ is increasing with $m$ as long as $m \leq M / 2$. We will therefore use the decreasing function $\beta B(m)$ to denote the ex ante expected per-player bias costs from having an optimally chosen $m$-member committee, where $m \leq M / 2$.

After making explicit the dependence on the variances of $F$ and $G$, we use (3) to write the ex ante expected total costs of having an optimally chosen $m$-member committee as

$m w+M \beta \sigma^{2}\left(m \mid \sigma_{x}^{2}\right)+M \beta B\left(m \mid \sigma_{\theta}^{2}\right)$.

Given our distributional assumptions, the average reduction in risk costs from adding one more manager will be smaller for smaller values of $\sigma_{x}^{2}$ 
(better public information). Similarly, the average reduction in bias costs will be smaller for smaller values of $\sigma_{\theta}^{2}$ (implying that all the biases are shrunk towards zero). Trivial comparative statics on $w, \sigma_{\theta}^{2}, \beta, M$, and $\sigma_{x}^{2}$ then yield:

RESULt 1: If $M$ is large, the ex ante expected size of the optimal committee is weakly smaller if it takes more time to make the decision, if biases are smaller and less important, if there are fewer players, and if public information is better.

Because the optimal committees with $m$ and $m+1$ members may have no common elements, it is difficult to characterize players with better management potential. To illustrate the range of possibilities and get richer results, we generalize the model by assuming that players may differ in terms of the variance of their private signal $\left(\sigma_{y j}^{2}\right)$, as well as the strength of their preference $\left(\beta_{i}\right)$. In this case the committee minimizes the sum of its losses by setting

$a_{m}=\mu\left(y_{1}, y_{2}, \ldots, y_{m}\right)+\Sigma_{m} \beta_{i} \theta_{i} / \Sigma_{m} \beta_{i}$.

Intuition suggests that players with representative preferences are better mangers, but if $M=5$ and the $\theta^{\prime}$ s are $-2,-1,0,1$, and 2, the best twomanager team need not include the player with $\theta=0$. If candidates differ in the strength of their preferences, the best two-manager team could consist of the players with $(\theta, \beta)=(2,1)$ and $(\theta, \beta)=(-1,2)$. Other considerations come into play if the candidates differ in the quality of their information, in which case it is possible that the player with $\theta=2$ is the best single manager. So managers with extreme preferences may supplant more moderate candidates, either because they can counterbalance other extremists, or because they have better information.

However, we can make some progress in the situation where alternative players are added to an existing, but randomly chosen, committee, including the case in which the additional player will be the only manager. We assume that the $\left(\sigma_{y i}^{2}, \beta_{j}\right)$ are drawn iid and that their distributions are sufficiently well-behaved to allow us to find the expected total costs of having a randomly chosen $m$-member committee as

$m w+\Sigma_{M} \beta_{i} \sigma^{2}(m)+\Sigma_{M} \beta_{i} B^{\prime}(m)$.

Using intuitive notation, we will write the ex ante expected costs of having a randomly chosen $m$-member committee plus player $j$ as

$(m+1) w+\Sigma_{M} \beta_{i} \sigma^{2}\left(m, \sigma_{y j}^{2}\right)+\Sigma_{M} \beta_{i} B^{\prime}\left(m, \beta_{j}\right)$. 
Comparing (4') and (6), it is obvious that the risk costs will decrease by a larger amount if $j$ has better information. To understand the behavior of the bias costs, note that the ex ante expected value of $\Sigma_{M} \beta_{i} \theta_{i}$ is zero, implying that we want to select $j$ to minimize the expected squared bias of the new committee $\mathrm{E}_{\beta} \mathrm{E}_{\theta}\left[\Sigma_{m} \beta_{i} \theta_{i}+\beta_{j} \theta_{j}\right]^{2} /\left[\Sigma_{m} \beta_{i}+\beta_{j}\right]^{2}$. If we first treat $\beta_{j}$ as a random variable and use $\mathrm{E}_{\beta} \mathrm{E}_{\theta} \Sigma_{m} \beta_{i} \theta_{i}=0$ in comparing different values of $\theta_{j}$, it is clear that $j$ is a better candidate if his squared bias is closer to zero, the ex ante expected value. If next we treat $\theta_{j}$ as a random variable and compare different values of $\beta_{i}$, integration reduces the expected bias costs to $\mathrm{E}_{\beta}\left[\Sigma_{m} \beta_{i} \sigma_{\theta}^{2}+\beta_{j} \sigma_{\theta}^{2}\right]^{2} /\left[\Sigma_{m} \beta_{i}+\beta_{j}\right]^{2}=\sigma_{\theta}^{2}$. So the value of $\beta_{j}$ does not matter for j's ex ante attractiveness as a candidate. Consistent with Homans (1950, p. 188), Simon (1951), and Simon (1976, p. 135) this gives:

RESULt 2: A member is ceteris paribus a better manager if his private information is more precise and on the average a better manager if his bias is smaller. The strength of his preferences does not matter.

We have tacitly assumed that any player asked would agree to serve as a manager. If this is not the case, the least suitable players, those with the largest biases, will be most eager to serve. More generally, the gains from increasing the size of the committee are often distributed quite unevenly among the players. If biases are important, a player can gain a lot from becoming a manager, but others get little, if any, of the gains. However, the fact that managers generally are paid more than nonmanagers suggest that the externalities of good management are large and that managers' gains from biasing decisions in their own favor are rather limited.

\section{Threatened Protest}

If nonmanagers can react to a decision they do not like, managers might want to avoid this by making a less biased decision than that in (1). We will now show how the resulting discipline may lower the bias costs incurred by nonmanagers and thus allow the group to use a smaller management team. To keep the exposition simple, we change two assumptions from the previous section. In terms of content, the strongest of these assumptions is that the posterior variance for practical purposes is zero. This could be the case because the signals are very good or because the number of managers is very large. The assumption is convenient because it allows us to abstract from informational rationales for protests. That is, nonmanagers may protest to have their preferences weighted more heavily in the decision, but not to bring more 
information to bear on it. The other change, which bears more on the derivation than on the interpretation of the results, is that we here look at $X=\{-1,1\}$, rather than $\mathbf{R}$. In this context, $\operatorname{argmin}_{a} \beta\left(a-x-\theta_{j}\right)^{2}$, player $j$ 's preferred action, equals $x$ if $-1<\theta_{j}<1$, whereas it is 1 if $1<\theta_{j}$ and -1 if $\theta_{j}<-1$. We confine attention to the interesting case in which the managers always prefer that $a=1$, the nonmanagers prefer $a=x$, and the latter is most efficient. This translates into the assumptions

$1<\Sigma_{m} \theta_{i} / m, \quad-1<\Sigma_{M / m} \theta_{i} /(M-m)<1, \quad$ and $-1<\Sigma_{M} \theta_{i} / M<1$.

We distinguish between cases in which the decision can be changed and cases in which it cannot. In the latter circumstances, we investigate the effect of contractual or otherwise credible enforcement.

\subsection{DECISIONS CAN BE CHANGED}

We model intervention by assuming that a protest by the $M-m$ nonmanagers will result in the decision being changed from $a_{m}$ to the level, in this case $a=x$, that minimizes the expected combined losses of all group members. That is, a protest leads to the same action as an $M$-person committee. Protesting will impose a cost of $c_{M / m}>0$ on each of the $M-m$ nonmanagers and a cost of $c_{m} \geq 0$ on each of the managers. We abstract from any coordination problems among the nonmanagers and assume that they protest $(P)$ if this reduces their combined expected losses by $(M-m) c_{M / m}$ or more, and otherwise remain quiet $(Q)$.

Let $x^{\prime}$ be the realized value of $x$ known to $m$. A strategy $\xi_{m}$ for the managers thus maps $x^{\prime} \in\{-1,1\}$ into $\{-1,1\}$, and a strategy $\xi_{M / m}$ for the nonmanagers maps $a \in\{-1,1\}$ into $\{P, Q\}$. We first propose a candidate equilibrium in which the managers set $a=1$ if $x^{\prime}=1$ and mix between -1 and 1 if $x^{\prime}=-1$, whereas the nonmanagers use a mixed protest strategy if $a=1$. Formally: $\xi_{m}(1)=1$ and $\xi_{m}(-1)=(-1,1)$ with probabilities $(1-h, h)$, whereas $\xi_{M / m}(1)=(P, Q)$ with probabilities $(p, 1-p)$, and $\xi_{M / m}(-1)=Q$. In this candidate equilibrium, if nonmanagers observe $a=1$, they assign posterior probability $h /(1+h)$ to $x^{\prime}=-1$ and complementary probability to $x^{\prime}=1$. We can now calculate expected losses from different choices. The nonmanagers' expected loss from $\xi_{M / m}(1)=P$ is

$(M-m) c_{M / m}+\beta\left(\Sigma_{M / m} \theta_{i}^{2}\right)$,

whereas their expected loss from $\xi_{M / m}(1)=Q$ is

$\beta \Sigma_{M / m}\left(2-\theta_{i}\right)^{2} h /(1+h)+\beta\left(\Sigma_{M / m} \theta_{i}^{2}\right) /(1+h)$. 
Because the candidate equilibrium has the nonmanagers mixing between these two choices, it has to satisfy

$c_{M / m}(1+h) /(4 \beta h)=1-\Sigma_{M / m} \theta_{i} /(M-m)$.

Looking next at the managers, their expected loss from $\xi_{m}(-1)=1$ is

$p\left[m c_{m}+\beta \Sigma_{m} \theta_{i}^{2}\right]+(1-p) \beta \Sigma_{m}\left(2-\theta_{i}\right)^{2}$,

whereas their loss from $\xi_{m}(-1)=-1$ is $\beta \Sigma_{m} \theta_{i}^{2}$. So the candidate equilibrium also has to satisfy

$c_{m} m p /[4 \beta(1-p)]=\Sigma_{m} \theta_{i}-m$.

This equilibrium exists if the parameters $\left(M, m, \beta, \theta_{m}, \theta_{M / m}, c_{m}, c_{M / m}\right)$ are such that (9) and (11) give $h$ and $p$ between 0 and 1. For example, if $M=2, m=1, \beta=1, \theta_{m}=2, \theta_{M / m}=0, c_{m}=1$, and $c_{M / m}=1$, we get $h=$ $1 / 3$ and $p=4 / 5$.

Looking at (9), we see that lower values of $c_{M / m}$, implying that it becomes cheaper for nonmanagers to protest, ceteris paribus result in smaller values of $h$. An alternative way to take advantage of a reduction in protest costs is to appoint fewer managers. To see this, recall that we are looking at a situation in which $\Sigma_{M / m} \theta_{i} /(M-m)<1<\Sigma_{m} \theta_{i} / m$, implying that the average nonmanager has smaller bias than the average manager. So the right side of (9), $1-\Sigma_{M / m} \theta_{i} /(M-m)$, will decrease in expectation if a randomly chosen manager is reassigned to the ranks of nonmanagers. The maximum rate of decrease will occur if, as is optimal, the most highly biased manager is reassigned. So we have shown the following two results:

RESULt 3: Holding committee size constant, managers exercise weakly more restraint if it is cheaper for nonmanagers to protest.

RESULt 4: On the average, the optimal committee size is weakly smaller if it is cheaper for nonmembers to protest. ${ }^{4}$

Although these results illustrate some advantages of cheap protests, there may also be disadvantages; particularly if protests are very costly to managers. To see this, we look at another candidate equilibrium in which managers set $a=-1$ regardless of the value of $x^{\prime}$, whereas nonmanagers protest if $a=1$. Suppose first that $x^{\prime}=1$ : If the managers set $a=-1$, they sustain an expected loss of $\beta \Sigma_{m}\left(2+\theta_{i}\right)^{2}$, whereas their loss from setting $a=1$ and loosing a protest is $m c_{m}+$ $\beta \Sigma_{m} \theta_{i}^{2}$. So the candidate equilibrium requires that

$c_{m}>4 \beta\left(1+\Sigma_{m} \theta_{i} / m\right)$.

4. In Wernerfelt (2006) a similar mechanism is used to explain the effect of renegotiation on contractual incompleteness. 
If $x^{\prime}=-1$, the candidate equilibrium demands that $a=-1$, giving managers a loss of $\beta \Sigma_{m} \theta_{i}^{2}$, which is smaller than $m c_{m}+\beta \Sigma_{m} \theta_{i}^{2}$, their loss from setting $a=1$ and winning a protest. So no additional restrictions are required to sustain $\xi_{m}(-1)=(-1)$. Looking next at the nonmanagers, suppose that they assign a probability $q$ to $x^{\prime}=-1$, contingent on observing the out-of-equilibrium action $a=1$. Their expected loss from not protesting is $(1-q) \Sigma_{M / m} \theta_{i}^{2}+q \Sigma_{M / m}\left(2-\theta_{i}\right)^{2}$, whereas their loss from protesting is $(M-m) c_{M / m}+\Sigma_{M / m} \theta_{i}^{2}$. The candidate equilibrium therefore requires that ${ }^{5}$

$c_{M / m}<4 q \beta\left[1-\Sigma_{M / m} \theta_{i} /(M-m)\right]$.

For the parameter values characterized by (12) and (13), protests are very cheap for nonmanagers, but expensive for managers. As a result, managers refrain from the efficient $\xi_{m}(1)=1$ because the gains do not justify the costs of facing (and winning) a protest. So if it is very cheap to protest, but expensive to be protested against, managers may ignore valuable private information.

RESULT 5: The threat of protests may reduce efficiency by giving managers reason to ignore private information.

This result is similar in spirit to those of Dessein (2002) and Prendergast (1993). Intuitively, the managers may decide not to act on some of their information in order to be spared the costs of justifying it after a possible protest. This may explain why organizations often set the threshold for protests above the minimum feasible level.

\subsection{DECISIONS CANNOT BE CHANGED/CONTRACTUAL CONTROL}

In many of the applications we have in mind, things happen so quickly that nonmanagers only learn of a decision once it has been implemented. To look at this case, we will assume that nonmanagers can make a credible commitment to punish committee members if they make what appears to be a sufficiently selfish decision. We will not clutter up the paper by explaining how the commitment is sustained, but we have in mind something like reputational concerns or contracts. Focusing again on the case in which managers prefer larger levels than nonmanagers, we assume that the latter engage in random auditing and that $a=1$ when $x^{\prime}=-1$ triggers a punishment in which each manager will incur a loss of $r_{m}>0$. In these circumstances it is easy to see that the threat

5. To perfectly characterize the conditions under which the candidate equilibrium exists, it may be possible to use some sort of refinement to eliminate the endogenous belief $q$ from (13). 
of punishment allows the optimal committee size to be weakly smaller. In fact, with sufficiently severe punishments, even the most extreme committee can be induced to maximize the joint payoffs of the entire group.

\section{Discussion}

We have argued that it takes time to be involved in decision-making and that this may cause groups to voluntarily cede decision rights to small committees. We identified several forces involved in the tradeoff and showed that delegation to smaller committees (or individuals) is more likely if decision-making is harder, if there is more public and less private information, and if preferences are better aligned. On the other hand, a decision more likely to be given to a larger committee if biases are diverse and public information is poor. Delegation to individuals or smaller committees is also easier if nonmanagers can use control systems to overturn or punish decisions. Although such systems force managers to be less selfish and allow committees to be smaller, they may cause committee members to ignore their private information. Players with better information and more typical preferences generally make better managers, but there are many exceptions to this. In committees with several members, one should expect to see diverse biases and information sets represented.

The model speaks directly to situations in which groups of peers allocate decision rights to committees. Compensation committees in partnerships and promotion committees in universities are two fairly clean examples, but the model should also capture some determinants of the size and composition of corporate boards.

It is interesting to hold the model up against the stylized fact that organizations typically assign decisions to individual managerscommittee size of one. Even very important and information intensive decisions are often charged to just one person. A possible explanation is that one is a corner solution: organizations face so many decisions and each takes so much time that it is uneconomical to have more than one manager involved in the vast majority of them. This is consistent with the fact that most large organizations go beyond the corner in which all decisions are made by a single manager. Instead, there is subdelegation: decisions are classified into types and a single manager is in charge of each type. Other possibilities go beyond the model: Bargaining and communication costs, which go up once more than one player is involved, could be important factors, or there may be a lot of informal joint decision-making involving different groups on an issue-by-issue basis. 
On the other hand, the one-member committees look like bosses in employment relationships, and the model's predictions about when we will see a boss and who it will be, has significant intuitive appeal: There is a single boss when a lot of decisions have to be made and the boss has very good information and representative biases. It is consistent with the view that the manager knows what should be done, that he will not abuse his authority, that he cares about what is done, that he has a big job, and that the other players find themselves in an employment relationship. This then suggests that one could build a theory of the firm based on the force of decision-making costs alone. The employment relationship would be defined as an implicit contract in which the employee has agreed to accept the decisions of his boss, while retaining the legal right to argue/quit. Independent contractors would be defined as players who negotiate over at least some decisions affecting the trading relationship.

We have made several convenient assumptions and thereby avoided important issues that warrant further research. First, our focus on maximization of joint payoffs has allowed us to ignore the incentives to accept committee membership and the associated role of side-payments within the group. The fact that managers normally are paid more than nonmanagers is consistent with the conjecture that the private benefits of control are quite small relative to the burden of decision-making and thus insufficient compensation for it. Secondly, it would be interesting to undertake a more explicit study of contracting and repeated decision-making and the role each of these can play in limiting the managers' ability to make selfish decisions. Third, we have unrealistically tied the contribution of information and the making of decisions together. It stands to reason that committee members will use their own information, but it would be interesting to look at a situation in which they can solicit input from others as well. Fourth, we portrayed protests as a mechanism for compensating for managerial biases, but abstracted from their informational effects. To the extent that protests lead to better information, both managers and nonmanagers benefit from them. The prospects of this may cause managers to exhibit less restraint than suggested by our analyses. Fifth, one could imagine a number of other dis-economies of larger committees: Costs may swell, information may be used less effectively, and members may free-ride.

\section{REFERENCES}

Aghion, P. and J. Tirole, 1997, "Formal and Real Authority in Organizations," Journal of Political Economy, 105, 1-29. 
Albaek, S. and C. Schultz, 1997, “One Cow, One Vote?" Scandinavian Journal of Economics, 99, 597-615.

Anderson, I., 1958, "Early Democratic Traditions in Scandinavia" in J.A. Lauwerys, ed., Development of Democratic Thought and Institutions in Denmark, Norway, and Sweden. Copenhagen, Denmark: Schultz, 69-77.

Bajari, P. and S. Tadelis, 2001, "Incentives versus Incentives: A Theory of Procurement Contracts," RAND Journal of Economics, 32, 387-407.

Barnard, C.I., 1968, The Functions of the Executive (Thirtieth Anniversary Edition), Cambridge, MA: Harvard University Press.

Black, D., 1958, The Theory of Committees and Elections, Cambridge, UK: Cambridge University Press.

Bolton, P. and A. Rajan, 2001, "The Employment Relation and the Theory of the Firm: Arm's Length Contracting vs. Authority," Working Paper, Princeton University.

Calvo, G. and S. Wellisz, 1986, "Supervision, Loss of Control, and the Optimal Size of the Firm," Journal of Political Economy, 86, 943-952.

Choi, J.J., D. Laibson, B. Madrian, and A. Metrick, 2006, "Saving for Retirement on the Path of Least Resistance," in E. McCaffrey and J. Slemrod, eds., Behavioral Public Finance: Towards a New Agenda, New York: Russell Sage Foundation, 304-351.

Crawford, V.P. and J. Sobel, 1982, "Strategic Information Transmission," Econometrica, 50, $1431-1452$.

Cremer, J., 1980, "A Partial Theory of the Optimal Organization of a Bureaucracy," The Bell Journal of Economics, 11, 683-693.

Dessein, W., 2002, "Authority and Communication in Organizations," Review of Economic Studies, 69, 811-838.

— , 2003, "Hierarchies versus Committees," Working Paper, University of Chicago.

Downs, A., 1957, An Economic Theory of Democracy, New York: Harper and Row.

Garicano, L., 2000, "Hierarchies and the Organization of Knowledge in Production," Journal of Political Economy, 108, 874-904.

Geanakoplos, J. and P. Milgrom, 1991, "A Theory of Hierarchies Based on Limited Attention," Journal of Japanese and International Economics, 5, 205-225.

Gilligan, T.W. and K. Krehbiel, 1987, "Collective Decision-Making and Standing Committees: An Informational Rationale for Restrictive Amendment Procedures," Journal of Law, Economics, and Organization, 3, 287-335.

Guest, R.H., 1956, "On Time and the Foreman," Personnel, 32, 478-486.

Harris, M. and A. Raviv, 2007, "A Theory of Board Control and Size," Review of Financial Studies, 20, forthcoming.

Hauser, J.R. and B. Wernerfelt, 1990, "An Evaluation Cost Model of Consideration Sets," Journal of Consumer Research, 16, 393-408.

Homans, G.C., 1950, The Human Group, New York: Harcourt, Brace, Jovanovich.

Madrian, B. and D. Shea, 2001, "The Power of Suggestion: Inertia in 401(k) Participation and Savings Behavior," Quarterly Journal of Economics, 116, 1149-1187.

Meagher, K., H. Orbay, and T. Van Zandt, 2004, “Market Contingent Managerial Hierarchies," Working Paper, INSEAD.

Mintzberg, H., 1973, The Nature of Managerial Work, New York: Harper and Row.

Persico, N., 2004, "Committee Design with Endogenous Information," Review of Economic Studies, 71, 165-194.

Perkins, K.B. and D.G. Poole, 1996, "Oligarchy and Adaptation to Mass Society in an AllVolunteer Organization: Implications for Understanding Leadership, Participation, and Change," Nonprofit and Voluntary Sector Quarterly, 25, 73-88.

Prendergast, C., 1993, "A Theory of "Yes Men"," American Economic Review, 84, 757-770.

Radner, R., 1993, "The Organization of Decentralized Information Processing," Econometrica, 61, 1109-1146. 
Sah, R.K. and J.E. Stiglitz, 1988, "Committees, Hierarchies, and Polyarchies," Economic Journal, 98, 451-470.

Segal, I., 2006, "Communication Complexity and Coordination by Authority," Advances in Theoretical Economics, 6, Forthcoming (http://www.bepress.com/bejte/advances/)

Simon, H.A., 1976, Administrative Behavior (Third Ed.), New York: Free Press.

— 1960, The New Science of Management Decision, New York: Harper and Row. ,1951, "A Formal Theory of the Employment Relationship," Econometrica, 19, $293-305$.

Stein, J., 2002, "Information Production and Capital Allocation: Decentralized vs. Centralized Firms," Journal of Finance, 57, 1891-1921.

Tadelis, S., 2002, "Complexity, Flexibility, and the Make-or-Buy Decision," American Economic Review, 92, 433-437.

Wernerfelt, B., 2006, “Renegotiation Facilitates Contractual Incompleteness," Working Paper, MIT.

— 1997, "On the Nature and Scope of the Firm: An Adjustment-Cost Theory," Journal of Business, 70, 489-514.

Whyte, W.F., 1943, The Street Corner Society, Chicago: University of Chicago Press.

Zbaracki, M.J., M. Ritson, D. Levy, S. Dutta, and M. Bergen, 2004, "Managerial and Customer Costs of Price Adjustment: Direct Evidence from Industrial Markets," Review of Economics and Statistics, 86, 514-533. 